\section{Adopt US recommendation on vision screening in older adults}

CMAJ recently published a guideline from the Canadian Task Force on Preventive Health Care for family physicians or other primary care providers that recommended against vision screening, defined as either asking a question about vision health or vision testing such as visual acuity, for Canadians 65 years of age or older based on "low-quality evidence."1 The methodology of the review is not being challenged. However, the conclusions are not supported and are being questioned by the Canadian Ophthalmological Society for several reasons.

The literature on which this guideline was based is from studies outside of Canada. Health care policies, such as public funding of routine eye examinations, differ by region, and this should be considered when making recommendations. In Canada, routine eye examinations performed by optometrists or ophthalmologists for older adults are not funded by governments in Saskatchewan, New Brunswick, Newfoundland and Labrador, and Prince Edward Island, which includes 460700 Canadians (7.4\%) aged 65 years or older who rely on family physicians as the entry point for eye care. ${ }^{2}$

Wilson and colleagues referenced the 2005 Canadian Community Health Survey and reported that $59 \%$ of adults 65 years or older consulted an eye care professional in the previous year. ${ }^{1,3}$ This statistic is misleading because it also included those with a known eye condition. For those without a known eye condition, only $51 \%$ of older adults living in a province with governmentinsured eye examinations had seen an eye care professional in the preceding year, and this decreased to $42 \%$ for those living in the four provinces without government coverage. ${ }^{3}$ The prevalence of eye disease increases with age; therefore, in this vulnerable population, more than $50 \%$ had not seen an eye care professional and are at risk, especially for eye disease that may be asymptomatic initially.

The guideline does not apply to certain groups, excluding those with "a condition known to predispose to vision impairment, such as glaucoma or diabetes."1 However, a physician may not be aware that a patient was in an excluded category unless they asked about vision issues. In addition, some potentially treatable eye diseases may not be known to the patient. For example, up to $50 \%$ of those with glaucoma in the industrialized world are unaware that they have the disease and are not receiving care. ${ }^{4-6}$ In 2012, nearly half of Canadians who were newly diagnosed with open-angle glaucoma had moderate or advanced disease at the time of diagnosis, and more than half of these patients were asymptomatic. ${ }^{7}$

Instead of recommending that primary care providers ignore vision health, they should be encouraged to educate patients about common risk factors for eye disease and the importance of routine eye examinations.

Given that the authors acknowledged there was no evidence of harm associated with screening adults for impaired vision and the evidence overall for this analysis was low quality, the Canadian Ophthalmological Society believes that a recommendation against screening seems to be extreme. Furthermore, the cost simply to inquire about a patient's vision health is low. For many older adults, a family physician may be their only contact with the health care system, and denying this opportunity to diagnose a vision-related health care issue is misguided.
The society suggests that the recommendations of the US Preventive Services Task Force, namely, no recommendation for or against screening, be adopted instead. ${ }^{8}$

\section{Yvonne M. Buys MD}

Ophthalmologist; president, Canadian Ophthalmological Society, Ottawa, Ont.

Cite as: CMAJ 2018 September 24;190: E1144. doi: $10.1503 / \mathrm{cmaj} .70063$

\section{References}

1. Wilson BJ, Courage S, Bacchus M, et al. Screening for impaired vision in community-dwelling adults aged 65 years and older in primary care settings. CMAJ 2018;190:E588-94.

2. Overview of provincial health coverage for optometric care [updated fall 2016]. Ottawa: The Canadian Association of Optometrists; 2016. Available: https:// opto.ca/sites/default/files/resources/documents/ prov_health_coverage_nov_2017.pdf (accessed 2018 May 29).

3. Canadian Community Health Survey - healthy aging (CCHS). Ottawa: Statistics Canada; 2010. Available: www23.statcan.gc.ca/imdb/p2SV. pl?Function=getSurvey\&SDDS=5146 (accessed 2018 May 29).

4. Sommer A, Tielsch JM, Katz J, et al. Relationship between intraocular pressure and primary open angle glaucoma among white and black Americans. The Baltimore Eye Survey. Arch Ophthalmol 1991;109:1090-5.

5. Mitchell P, Smith W, Attebo K, et al. Prevalence of open angle glaucoma in Australia - The Blue Mountains Eye Study. Ophthalmology 1996;103: 1661-9.

6. Anraku A, Jin YP, Butty Z, et al. The Toronto epidemiology glaucoma survey: a pilot study. Can $\mathrm{J}$ Ophthalmol 2011;46:352-7.

7. Buys YM, Gaspo R, Kwok K; Canadian Glaucoma Risk Factor Study Group. Referral source, symptoms, and severity at diagnosis of ocular hypertension or open-angle glaucoma in various practices. Can J Ophthalmol 2012;47:217-22.

8. US Preventive Services Task Force (USPSTF); Siu AL, Bibbins-Domingo K, Grossman DC, et al. Screening for impaired visual acuity in older adults: US Preventive Services Task Force recommendation statement. JAMA 2016;315:908-14.

Competing interests: Yvonne Buys is the president of the Canadian Ophthalmological Society. 